\title{
Invasive red king crabs feed on both spawned-out capelin and their eggs
}

\author{
Nina Mikkelsen, Torstein Pedersen* \\ Department of Arctic \& Marine Biology, Faculty of Biosciences, Fisheries \& Economics, UiT The Arctic University of Norway, \\ 9037 Tromsø, Norway
}

\begin{abstract}
The aim of the present study was to test the hypothesis that the invasive red king crab Paralithodes camtschaticus may hamper capelin (Mallotus villosus) recruitment through egg consumption. Field studies $(2005,2006)$, laboratory experiments (2011), and models of consumption were applied. To explore the response of the predator to prey density, crab abundance and capelin egg density were estimated in stratified study areas. Stomach evacuation rates of capelin eggs in red king crab stomachs were investigated experimentally, and the average evacuation time estimated to be $5.38 \mathrm{~h}$ at $2.9^{\circ} \mathrm{C}$. The average evacuation time was applied to a consumption model where uncertainty in input values was assessed by Monte Carlo simulation. Estimated egg consumption values were $0.04 \%$ and $2.23 \%$ of the total number of eggs in studied spawning areas, in 2005 and 2006, respectively. The high variability in quantity of eggs in stomachs generated most of the uncertainty in consumption estimates. Red king crabs did not show an aggregative response to capelin egg density, nor was the magnitude of egg consumption correlated with egg density. Dead post-spawn capelin was a major and more important prey than eggs for red king crab. Our findings imply that semelparity in Barents Sea capelin may lead to predator swamping, thereby reducing capelin egg consumption by the invasive red king crab.
\end{abstract}

KEY WORDS: Mallotus villosus · Paralithodes camtschaticus · Recruitment · Fish egg consumption · Decapod digestion · Predator response

\section{INTRODUCTION}

Mortality rates in marine fish eggs are generally high (Dahlberg 1979, Bailey \& Houde 1989, Leggett \& DeBlois 1994), and predation is probably the biggest single cause of mortality in young stages of fishes (Houde 2002). Predation mortality is therefore generally important in regulating marine fish recruitment (Bailey \& Houde 1989), and recruitment failures have been the main cause of the stock collapses experienced by Barents Sea capelin (Gjøsæter et al. 2009). Demersal spawners deposit their eggs on the sea floor, and if no egg-guarding behaviour is provided, the eggs are exposed to predation by benthic feeders. The eggs of demersal spawners, such as the capelin Mallotus villosus, often occur in dense aggre-

${ }^{*}$ Corresponding author: torstein.pedersen@uit.no gations and sometimes attract high densities of fishes and other predatory animals (Frank \& Leggett 1984, Bunn et al. 2000) and have been observed to experience high mortality (Dragesund \& Nakken 1973, Nakashima \& Wheeler 2002, Nilsson 2006).

Predators are classified as generalists in their feeding behaviour if they eat a variety of prey and target the most abundant prey species (Bax 1998). However, alternative prey may relax predation on other prey (Godiksen et al. 2006, Hallfredsson \& Pedersen 2007) in generalist feeding predators (Tschanz et al. 2007), which may also be swamped if very high abundance of prey saturates the predators (Ims 1990, Holt \& Lawton 1994). Nevertheless, a generalist may feed solely on one specific prey if it occurs in high densities, as shown by the amphipod Calliopius

(C) The authors 2017. Open Access under Creative Commons by Attribution Licence. Use, distribution and reproduction are unrestricted. Authors and original publication must be credited. 
laeviusculus, commonly classified as a feeding generalist (DeBlois \& Leggett 1993b). The amphipod fed almost exclusively on eggs from beach spawning capelin in Newfoundland, resulting in a predation mortality ranging from 5 to $30 \%$ of the total egg deposition (DeBlois \& Leggett 1993a).

The capelin is a short-lived semelparous species (Christiansen et al. 2008) with a circumpolar distribution. Capelin from the northeast Atlantic are typically demersal spawners, while capelin from the northwest Atlantic are primarily beach spawners (Carscadden \& Vilhjalmsson 2002). The Barents Sea capelin is a commercially exploited fish, and the largest capelin stock in the world, with yearly landings ranging from 66000 to $1123000 \mathrm{t}$ over the past 25 yr (ICES 2014), excluding years when fisheries were closed due to low spawning-stock biomass. Capelin is also an important forage fish for several predators (Gjøsæter \& Bogstad 1998, Bogstad \& Gjøsæter 2001, Dolgov 2002).

The Barents Sea capelin spawns off the coast of northern Norway and northwest Russia at depths commonly $<75 \mathrm{~m}$, and bottom temperatures during the time of egg incubation range from $1.5-6.5^{\circ} \mathrm{C}$ (Sætre \& Gjøsæter 1975, Fridgeirsson 1976). During spawning activity, capelin actively mix their eggs with bottom substrate, to which eggs also adhere (Fridgeirsson 1976). The preferred spawning substrate is pebbles or gravel with a grain size of 5$15 \mathrm{~mm}$ (Sætre \& Gjøsæter 1975), which prevents dispersal of the eggs by sea currents (Templeman 1948). Barents Sea capelin die after spawning (Gjøsæter 1998), and the absolute semelparity of this capelin stock has been documented in the field, where large quantities of dead capelin were found on the sea floor close to spawning sites in the middle of the spawning season (Bakke \& Bjørke 1973, Sætre \& Gjøsæter 1975), and by laboratory experiments (Christiansen et al. 2008). This spawning strategy (in its lack of eggguarding behaviour) leaves the eggs vulnerable to benthic feeders, and as a result, egg mortality due to predation is expected to be high in all capelin stocks (Sætre \& Gjøsæter 1975, Frank \& Leggett 1981, DeBlois \& Leggett 1993a). Predators may aggregate at spawning sites, because of both high egg density and the presence of dead or dying post-spawned capelin.

Some identified capelin egg predators include: the amphipod C. laeviusculus (DeBlois \& Leggett 1991), green sea urchin Strongylocentrotus droebachiensis (Crook \& Davoren 2016), capelin (Templeman 1948, Slotte et al. 2006), haddock Melanogrammus aeglefinus (Sætre \& Gjøsæter 1975, Dolgov 2002, Bogetveit et al. 2008), winter flounder Pseudopleuronectes americanus (Frank \& Leggett 1984), and the diving ducks Somateria mollissima, $S$. spectabilis and Clangula hyemalis (Sætre \& Gjøsæter 1975). A new potential egg predator, the invasive red king crab Paralithodes camtschaticus, entered the spawning sites of Barents Sea capelin in the 1990s (Britayev et al. 2010), and has been documented to feed on capelin eggs (Anisimova et al. 2005).

The red king crab was introduced to the Kola fjord, Russia, by Russian scientists over the period 19601969, with the aim of establishing a commercial stock (Orlov \& Ivanov 1978). By 1994, the crab had dispersed into Norwegian waters (Britayev et al. 2010), where it is still expanding its distribution area along the coast of northern Norway (Windsland et al. 2014). Mature red king crabs migrate to shallow waters in the spring to moult and mate (Sundet \& Hjelseth 2010), and their distribution area from February to April overlaps with spawning sites of capelin along the coast of northern Norway and the Kola Peninsula, Russia.

Commonly, the red king crab is described as a generalist feeding decapod (Britayev et al. 2010). It displays a number of different feeding strategies, such as grasping and tearing apart of larger prey, scooping up sediment by the lesser chela and sieving it through the third maxillipeds, or crushing scallops and picking out only the flesh (Jørgensen 2005). The heavy mastication of food items in crustaceans makes the identification of prey during stomach content analysis difficult, and soft tissue may be underestimated in field studies (Sarda \& Valladares 1990). This can introduce bias towards calcified and prey items which are slowly digested, as these are more frequently identified in crab stomachs. The most frequent prey groups identified in the red king crab in Norwegian waters are bivalves, polychaetes, algae, gastropods, echinoderms and some fish (Sundet et al. 2000, Haugan 2004).

Attempts to study and quantify the ecological effects of the red king crab on fish species in the Barents Sea have been scarce. Anisimova et al. (2005) provided a rough estimate of capelin egg consumption by the red king crab. They found that the egg consumption during the spawning season in 2001 amounted to 37 of the 130000 tons of eggs available in the Russian part of the Barents Sea. In another study carried out in 2003, the estimated consumption of lumpsucker Cyclopterus lumpus eggs by the red king crab corresponded to about one-third of the commercial catches of the same roe in tons and was considered to influence lumpsucker recruitment (Mikkelsen \& Pedersen 2012). Hypothetically, the 


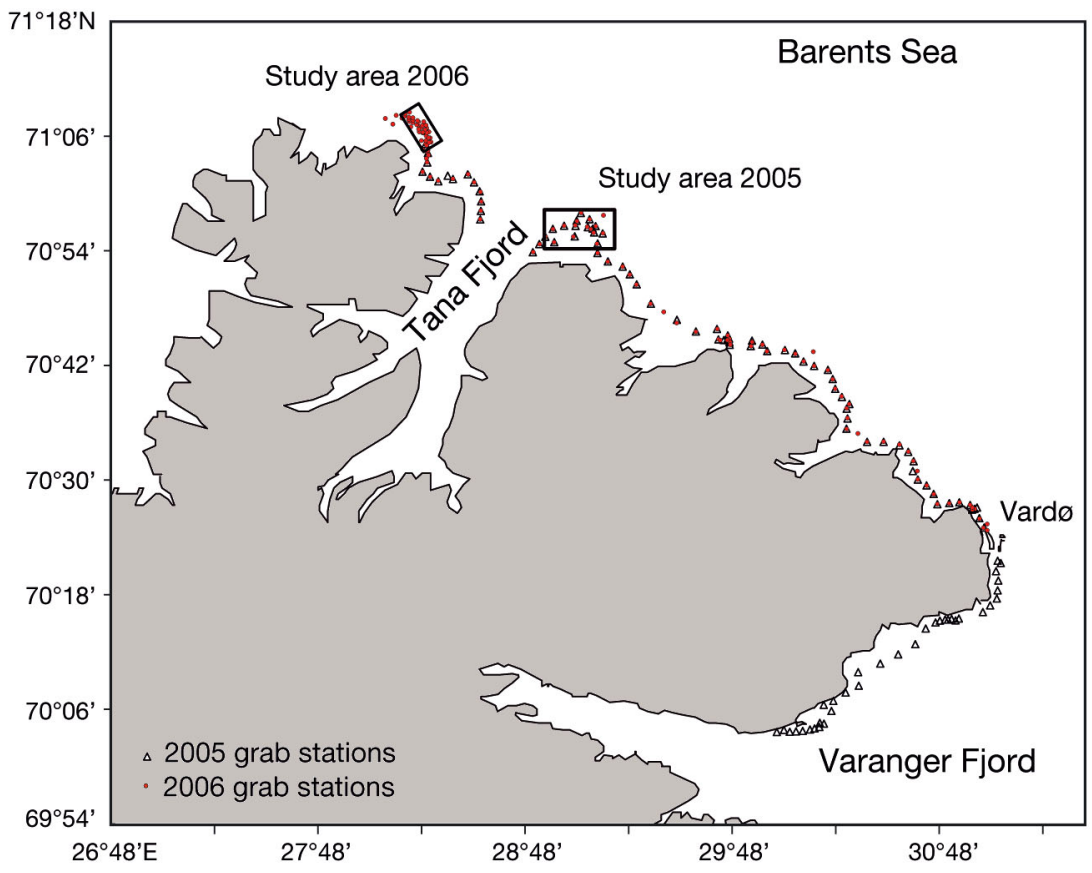

Fig. 1. Survey areas off the coast of Finnmark, northern Norway. Grab stations in 2005 and 2006 are shown. Rectangles: study areas with spawning sites of Barents Sea capelin Mallotus villosus in 2005 and 2006

post-spawned capelin as alternative prey, by the invasive red king crab, and evaluate the potential effects on capelin recruitment. We wanted to test the following hypotheses: (1) red king crabs feed on both capelin eggs and dead spent capelin, (2) consumption of capelin eggs by the red king crab increases with increasing capelin egg density, (3) red king crabs demonstrate aggregative response to high egg density, (4) stomach evacuation rates of capelin eggs in red king crabs can be estimated experimentally and (5) consumption of capelin eggs by the red king crab hamper the recruitment of Barents Sea capelin.

The approach to this study was to locate spawning areas of capelin, by an initial grab survey, within the distribution area of red king crab on the coast of Finnmark, northern Norway. When capelin spawning areas were located, we designed a second stratified survey with grab stations to estimate egg density and crab trawl sta-

presence of the red king crab may affect capelin recruitment, and these crabs may also compete with native species such as cod Gadus morhua and haddock feeding on dead post-spawn capelin on the seabed. To evaluate the potential effects of predation by the red king crab on capelin recruitment, it is important to estimate consumption of capelin eggs as well as capelin, in which dead post-spawn individuals may serve as an alternative prey and influence predation rates on fish eggs.

Daily ration models have been applied to estimate food consumption in crustaceans (Maynou \& Cartes 1998, Cristo \& Castro 2005). The most frequently used models to estimate gastric evacuation rates of crustaceans are exponential decay models (Hill 1976, Sarda \& Valladares 1990, Cristo 2001), although an ogive model has been used to estimate the evacuation of lumpsucker eggs in red king crabs (Mikkelsen \& Pedersen 2012). One approach to estimate daily rations uses data on average stomach content and the integral of the gastric evacuation function (Olson \& Boggs 1986). To estimate the consumption of eggs, knowledge of the stomach content and abundance of these crabs at capelin spawning sites, as well as stomach evacuation rate of capelin eggs, is required.

The main objectives of this study were to examine the magnitude of predation on capelin eggs and dead tions to estimate abundance and obtain stomach samples of red king crab. The resulting data were used to investigate if the crab showed an aggregative response to egg density and to study if the magnitude of egg predation by the red king crab was related to capelin egg density. An estimate of the evacuation rate of capelin eggs from crab stomachs was obtained from a laboratory experiment and applied to a consumption model to estimate the quantity of eggs consumed by red king crabs at the spawning areas studied. We used Monte Carlo (MC) simulations to take into account the uncertainty in input parameters when estimating consumption of capelin eggs.

\section{MATERIALS AND METHODS}

\section{Biological sampling}

Data and samples were collected during surveys aboard R/V 'Johan Ruud' in April 2005 and 2006 (Fig. 1). Selection of survey areas was based on knowledge of historical capelin spawning sites (Gjøsæter 1998), as well as information from local fishermen. Historical spawning sites west of $27^{\circ} 39^{\prime} \mathrm{E}$ were omitted, as they were not within the distribution area of red king crab. An adaptive strategy for sampling 


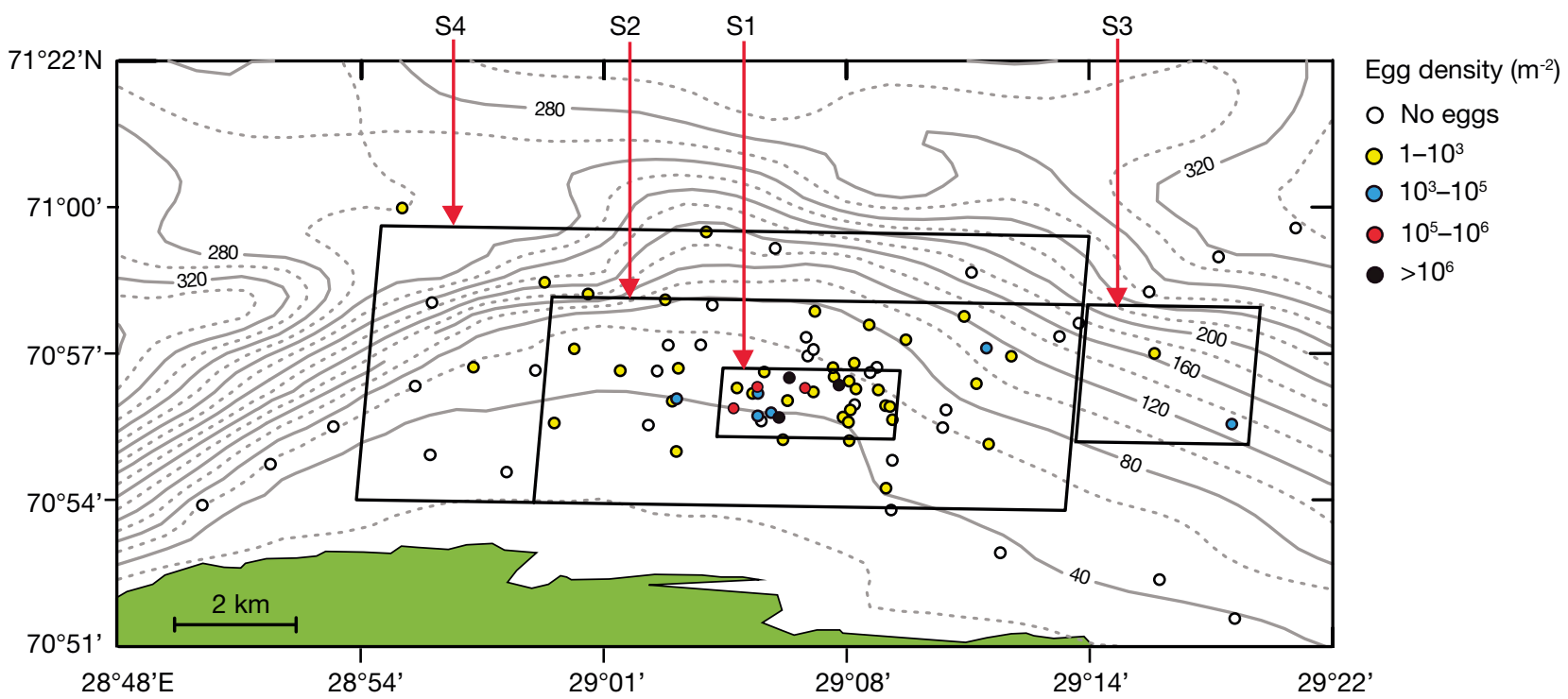

Fig. 2. Study area in 2005 with depth contours (m) and strata S1-S4. Grab sample positions from both Surveys I and II and Mallotus villosus egg densities in grab samples are shown

with a 2-phase approach survey (Francis 1984) was used. The objective of the first survey (Survey I) was to locate spawning areas of capelin (Rankine \& Morrison 1989). Furthermore, information from Survey I was employed to allocate sampling effort during the second stratified random survey (Survey II) (Francis 1984).

\section{Capelin eggs}

During Survey I, a van Veen grab with a sampling area of $0.1 \mathrm{~m}^{2}$ was used and a distance of $1 \mathrm{n}$ mile was sailed between grab stations taken at depths with suitable spawning substrates. When signs of predator aggregations of diving ducks and fish were observed, additional grabs were taken in between the pre-selected grabbing stations. Spawning sites were identified from observations of high egg density in substrates from additional grabs within $<0.5 \mathrm{~km}$ distance. In 2006, the area southwest of Vardø $\left(70^{\circ} 22^{\prime} \mathrm{N}, 31^{\circ} 06^{\prime} \mathrm{E}\right)$ (Fig. 1) was not surveyed because there were no recordings of spawning capelin there during the weeks prior to our survey.

After spawning sites were located in Survey I, Survey II was conducted using a random stratified sampling design where the positions of grab stations were randomly selected within 4 and 3 strata, in 2005 and 2006, respectively. The number of grab stations was increased in the stratum with the highest egg density identified during Survey I in order to reduce variance in egg density estimates within that stratum.
The spawning site found in $2005\left(70^{\circ} 55^{\prime} \mathrm{N}, 29^{\circ} 06^{\prime} \mathrm{E}\right)$ was located east of Tana Fjord (Fig. 1). The surveyed stratified area was $136 \mathrm{~km}^{2}$ (Fig. 2), and was divided into 4 strata, S1-S4 (Table 1). The highest egg density was recorded in Stratum S1. S3 was added because one station with high egg density (blue dot) was found in the eastern part of S2 (Fig. 2). The spawning site found in $2006\left(71^{\circ} 06^{\prime} \mathrm{N}, 28^{\circ} 17^{\prime} \mathrm{E}\right)$ was found west of Tana Fjord (Fig. 1). The surveyed stratified area was $23.1 \mathrm{~km}^{2}$ (Fig. 3) and was divided into 3 parallel strata, S5-S7 (Table 1, Fig. 3). The highest egg density was recorded in S6. At least 2 grab samples were taken in each stratum.

Egg density was classified into 5 categories, and the classification method employed was similar to that used by Sætre \& Gjøsæter (1975). The weight

Table 1. Area by stratum in stratified study areas (SA) in 2005 and 2006, and grab samples by strata from Survey II

\begin{tabular}{|c|c|c|c|c|c|}
\hline \multirow[t]{2}{*}{ Year } & \multirow[t]{2}{*}{ Stratum } & \multirow[t]{2}{*}{$\begin{array}{l}\text { Area } \\
\left(\mathrm{km}^{2}\right)\end{array}$} & \multirow{2}{*}{$\begin{array}{l}\text { Sample } \\
\text { (n) }\end{array}$} & \multicolumn{2}{|c|}{$\begin{array}{l}\text { - Grab stations } \\
\quad \text { Depth }(\mathrm{m})\end{array}$} \\
\hline & & & & Mean \pm SD & Range \\
\hline \multirow[t]{5}{*}{2005} & S1 & 7.58 & 22 & $45.7 \pm 6.5$ & $37-71$ \\
\hline & S2 & 60.68 & 28 & $65.2 \pm 28.9$ & $26-148$ \\
\hline & S3 & 15.17 & 2 & $147.0 \pm 24.0$ & $130-164$ \\
\hline & $\mathrm{S} 4$ & 53.03 & 8 & $129.1 \pm 61.9$ & 28-196 \\
\hline & SA & 136.46 & 60 & & \\
\hline \multirow[t]{4}{*}{2006} & S5 & 7.11 & 20 & $57.1 \pm 13.7$ & $40-83$ \\
\hline & S6 & 7.99 & 48 & $50.0 \pm 10.1$ & $24-70$ \\
\hline & S7 & 8.01 & 17 & $54.0 \pm 13.7$ & $37-87$ \\
\hline & SA & 23.11 & 85 & & \\
\hline
\end{tabular}




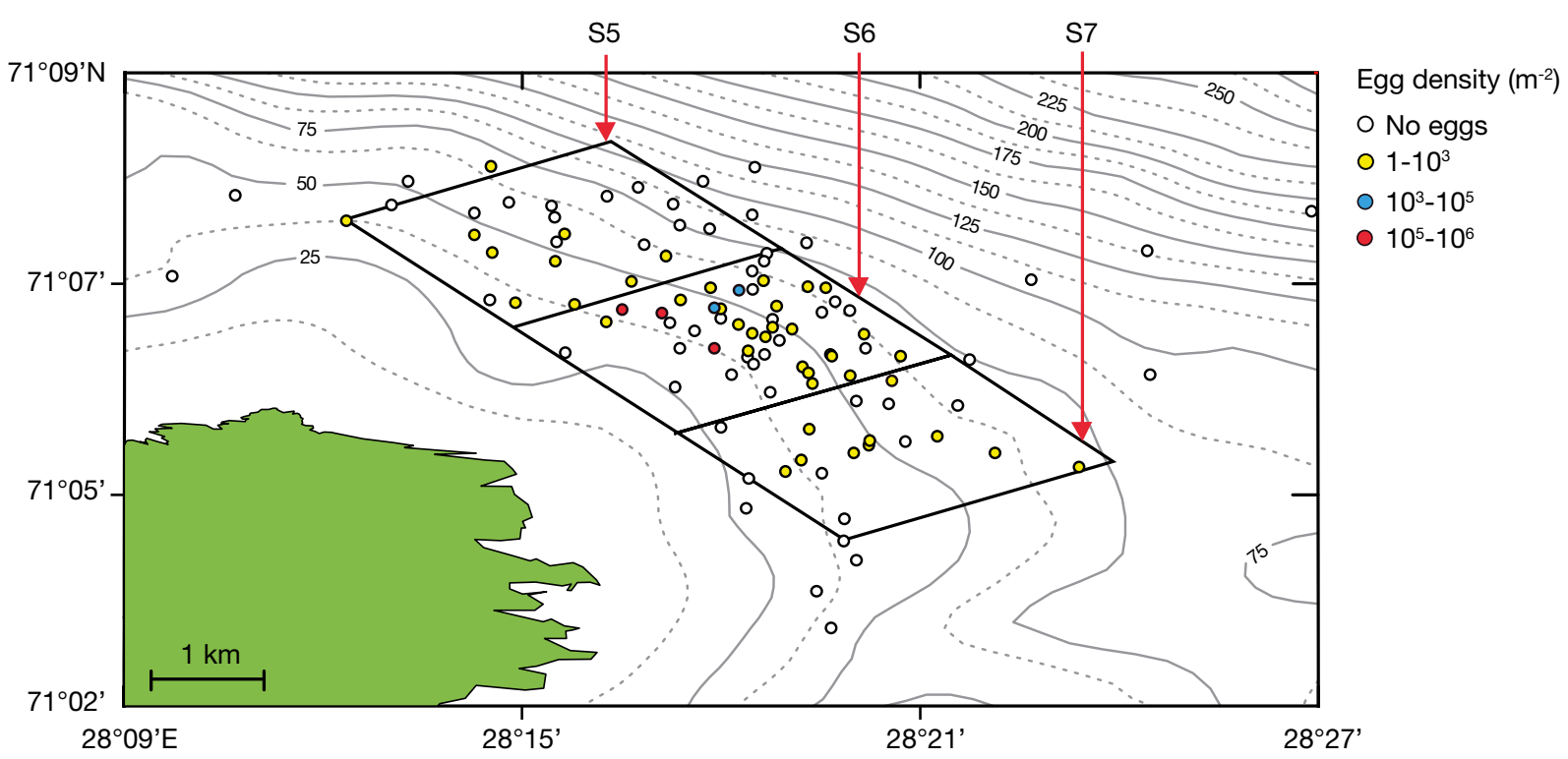

Fig. 3. Study area in 2006 with depth contours (m) and strata S5-S7. Grab samples from both Surveys I and II and Mallotus villosus egg densities in grab samples are shown

and volume of the grab sample was noted. Subsequently, the grab sample was poured into a bucket, the surface water was sieved through a $0.9 \mathrm{~mm}$ mesh size sieve, and capelin eggs retained on the sieve were counted if they were alive and well developed. From measurements of volumes of most samples $(\mathrm{n}=$ 84) and area sampled by the grab $\left(0.1 \mathrm{~m}^{2}\right)$, the average depth of the sample was estimated to be $2.3 \mathrm{~cm}$ (SD: $2.2 \mathrm{~cm}$ ). The number of eggs in the grab was estimated using a 2-stage subsampling. At sea, the substrate was thoroughly mixed using a small shovel, and if eggs were visually detected on the sieve or in the substrate, 5 subsamples of approximately $20 \mathrm{~g}$ each were randomly taken, otherwise only 3 subsamples were taken. Subsamples were frozen at $-18^{\circ} \mathrm{C}$ for later egg counting.

\section{Red king crab}

Red king crabs were collected for stomach analysis and abundance estimates by using a specially designed beam trawl throughout a $24 \mathrm{~h}$ period, previously used in surveys for stock assessment by the Institute of Marine Research (Bergen, Norway). The crab trawl was $6 \mathrm{~m}$ wide, $1 \mathrm{~m}$ high, and was equipped with a $135 \mathrm{~mm}$ mesh size polyethylene net (Sundet \& Berenboim 2008). The hauling speed was approximately $1.65 \mathrm{kn}$. It was not possible to use a fixed standardised trawling distance because of the changing and rocky bottom topography. Four hauls were also performed with a shrimp bottom trawl in 2005, to catch fish for stomach analysis for another study not included in this paper. However, as red king crabs were caught during 4 of these hauls (Table S1 in the Supplement at www.int-res.com/articles/suppl/m563 p139_supp.pdf), stomach analysis of these crabs ( $\mathrm{n}=$ 59) were included the current study. One pelagic trawl haul was also conducted to sample capelin to ease identification of capelin remains in the crab stomach by comparing prey fragments in crab stomachs to freshly masticated capelin.

All crab and shrimp trawl hauls were taken inside the stratified area in 2005, but in 2006, 6 crab trawl hauls (non-strata stations) with a catch of 10 crabs were done outside of the stratified area (Table S1). A total of 125 and 60 crabs were captured for stomach analysis, in 2005 and 2006, respectively. All collected crabs were measured by carapace length $(\mathrm{CL})$ to the nearest mm using a vernier caliper (Table S2 in the Supplement). Sex was determined according to standard procedures (Donaldson \& Byersdorfer 2005). Crabs were killed by cutting the isthmus before lifting the carapace, and the crabs were then cut in halves longitudinally. Stomachs, usually attached to the carapace, were removed and preserved in $4 \%$ buffered formaldehyde.

\section{Laboratory processing}

In the laboratory, each of the subsamples was weighed and spread evenly out onto a transparent centimetre-scaled foil after thawing, and the number 
of squares covered were counted $\left(\mathrm{N}_{\mathrm{sq}}\right)$. Five random $2 \times 2 \mathrm{~cm}$ squares were selected for egg counting. The average number of eggs per square $\left(\mathrm{X}_{\mathrm{sq}}\right)$, the $\mathrm{SD}$, and the coefficient of variation $\left(\mathrm{CV}=\mathrm{SD} / \mathrm{X}_{\mathrm{sq}}\right)$ was calculated. If the $\mathrm{CV}$ was $>2.0,3$ additional squares were counted until the CV was $<2.0$. The total number of eggs in each subsample was calculated $\left(\mathrm{X}_{\mathrm{sq}} \times \mathrm{N}_{\mathrm{sq}}\right)$.

The formalin-preserved stomachs $\left(\mathrm{N}_{2005}=125\right.$, $\mathrm{N}_{2006}=60$ ) were rinsed in fresh running water for $24 \mathrm{~h}$ before analysis. Fish eggs were identified and all whole eggs with an unbroken chorion were counted. Capelin was identified by observing features such as size of dorsal vertebrae, eye lenses, otoliths, bones, and skin and comparing these features with those of 'fresh' frozen samples of capelin. We pooled stomach data for both sexes because previous studies have shown no sex-related differences in diet (Feder \& Paul 1980, Mikkelsen \& Pedersen 2012). Empty stomachs were also included.

\section{Stomach evacuation experiment}

An experiment was designed to estimate the stomach evacuation rate of capelin eggs in red king crabs at an ambient temperature of $2.9^{\circ} \mathrm{C}$, which is within the range of bottom temperature at capelin spawning sites along the coast of northern Norway (Sætre \& Gjøsæeter 1975). The experiment ran between March 27 and April 6, 2011. The collection of experimental animals and capelin eggs (Fig. S1 in the Supplement) is described in Mikkelsen (2013).

Upon arrival at the research facilities, crabs were individually marked, and CL and wet body weight (BW) (g) were measured. The crabs were randomly distributed in 2 rectangular $(2.5 \times 1.1 \mathrm{~m})$ storage tanks with water depth of $30 \mathrm{~cm}$ (Fig. S2). The tanks were supplied with natural seawater at $2.9^{\circ} \mathrm{C}$, salinity of $33 \%$ and photoperiod of $5 \mathrm{~h}$, comparable to daylight conditions at shallow spawning grounds of the Barents Sea capelin. Eighteen crabs were placed in Tank A and 15 in Tank B. Two hours after being placed into storage tanks, the crabs were fed 20 dead capelin and 10 rectangular (approximately $10 \times 2 \times$ $1.5 \mathrm{~cm}$ ) clumps of capelin eggs per tank (approximately 112220 eggs, given a mean number of eggs in each egg clump of 11222 ). Most crabs had started eating within $2 \mathrm{~h}$, and after $24 \mathrm{~h}$, the only prey remaining in both storage tanks was a substantial amount of unconsumed eggs at the bottom of the tanks. When crabs destroyed the clumps of capelin eggs during feeding, most of the eggs at the bottom of the tank became unavailable for the crabs due to the construction of the storage tanks. During the acclimation and storage period, crabs were fed capelin $(n=20)$ and clumps of capelin eggs $(n=15)$ every other day in the storage tanks, which were cleaned every day. It was considered important to familiarise the crabs caught outside of the capelin spawning areas with this prey. Crabs seemed calm and acclimated within $2 \mathrm{~d}$ after arrival.

The production of capelin egg clumps that were used as prey in the experiment is described in Mikkelsen (2013). Upon arrival at the research facility, eggs were treated with Buffodine for disinfection and were distributed in gratings in 5 circular egg incubators with a diameter of $35 \mathrm{~cm}$ (Table S3 in the Supplement), which were covered with black lids to prevent exposing the eggs to light.

Experimental animals were deprived of food for $44 \mathrm{~h}$ before being transferred to individual experimental tanks (Fig. S3, Table S3). Only calm, actively feeding crabs $(\mathrm{n}=18)$ with a mean BW of $1422 \mathrm{~g}$ (Table S4 in the Supplement) were used to fit the stomach evacuation rate model. Crabs were offered one clump of capelin eggs as prey, adjusted to individual crab weight to obtain an average prey weight of $1.0 \%$ of BW (Table S4), which is within the range of the daily ration $(0.30-2 \%)$ of the red king crab in the field (Tarverdieva 1978, Gudimov et al. 2003). Unconsumed eggs were removed from the tank after $20 \mathrm{~min}$ and weighed so that the number of eggs consumed from each egg clump could be estimated. Crabs were killed hourly, by using the same procedure used during fieldwork, 1-14 h after feeding at predetermined slaughter times. Stomachs were immediately removed and fish eggs with unbroken chorions were counted. Broken chorions were often present in pieces, making it impossible to count them to whole eggs.

\section{Data analysis}

Capelin egg density

The total number of eggs in a grab sample was estimated from the average egg counts from the subsamples, the weight of the subsamples, and the total weight of the grab sample. The estimated total number of eggs per grab sample was used to calculate mean egg density $\left(\mathrm{m}^{-2}\right)$, with SD and $95 \% \mathrm{CI}$ for each stratum and year by MC estimation using PopTools version 3.2.3 in Excel 2010 (Hood 2010), with data from Survey II where grab samples in each stratum were bootstrapped 1000 times. CV was also calcu- 
lated. All other statistical analyses in this paper were performed using SYSTAT 13.1 software and a level of significance at $\alpha=0.05$ was applied.

The centre position of the spawning area (CSA) was calculated by multiplying the number of eggs in each of the grab stations from Surveys I and II by the latitude or the longitude of the station. The results were then divided by the total number of eggs found throughout Surveys I and II and the resulting latitude and longitude were defined as the CSA.

\section{Red king crabs}

Crab samples used for stomach analysis from 2005 and 2006 were compared with regard to sex and CL. CL data were log-transformed and analysed for differences in CL by year using a 2-sample $t$-test, assuming separate variance in the samples. The frequency of occurrences (FO\%) of capelin eggs and capelin were calculated as the number of stomachs containing the identified prey group, expressed as a percentage of all analysed stomachs.

\section{Probability functions for occurrence of capelin eggs in crab stomachs}

In addition, we employed backward logistic regression using the Blogit procedure in SYSTAT 13.1 to investigate whether the occurrence of capelin eggs or capelin in red king crab stomachs was affected by egg density, distance from the midpoint of the trawl track to CSA, the sampling year (2005 and 2006), and crab size by CL (mm). We expected smaller crabs to feed more frequently on eggs, as the larger crabs would probably prefer larger prey such as dead capelin when capelin is available. The logistic model applied was:

$$
P(x)=\frac{1}{\left(1+\mathrm{e}^{-z}\right)}
$$

where $P(x)$ gives the probability of prey occurrence, and $z$ is a linear function of the explanatory variables (Zuur et al. 2007). $Z$ is described by $g(x)$ for the occurrence of capelin eggs:

$$
\begin{aligned}
g(x)= & \beta_{0}+\beta_{1} E D+\beta_{2} D I S T+\beta_{3} Y R \\
& +\beta_{4}(E D \times Y R)+\beta_{5} C L
\end{aligned}
$$

where $\beta_{0}$ is a constant, $E D$ is egg density $\left(\log _{10}\right.$ (Eggs $\left.\left.\mathrm{m}^{-2}\right)+1\right)$ ), DIST is the distance $(\mathrm{km})$ from the midpoint of the trawl track to the CSA, YR is the dummy variable for year, $E D \times Y R$ is the interaction between egg density and year, and $C L$ is carapace length. The logistic regression was fitted to data from individual crabs $(n=185)$ from both sampling years. If the effect of $Y R$ was found to be significant, the function was fitted separately for $2005(\mathrm{n}=125)$ and $2006(\mathrm{n}=60)$. Variables were eliminated from $g(x)$ (Eq. 2) by an iterative process where the model was estimated to convergence, and the variable with the largest pvalue above 0.05 was removed. The procedure was repeated until all remaining effects had p-values $<0.05$.

The reference level for full models was one, but if $D I S T$ was removed, while $E D$ was retained, the reference level was changed to zero for $g(x)$, expecting zero occurrences of capelin eggs at zero egg density. The fit of the model was evaluated using the likelihood ratio test and statistical tests of individual predictors (estimate, SE, p-value and $95 \% \mathrm{CI}$ ), and the classificatory power of the model was determined by the proportion of successfully predicted responses (sensitivity) and references (specificity).

For crabs with eggs in their stomachs, the potential correlation between the number of eggs per stomach and $E D\left(\log _{10}\left(\right.\right.$ Eggs $\left.\left.\left.^{-2}\right)+1\right)\right)$, and DIST $(\mathrm{km})$ from the midpoint of the trawl track to CSA, was investigated using the Spearman rank correlation coefficient $\left(\mathrm{r}_{\mathrm{S}}\right)($ Zar 1999).

Red king crab abundance and aggregative response

In 2005, a total of 14 crab trawl hauls of approximately 26 min duration were taken in the 4 strata (Table 2), with an average area covered per haul of $8.6 \times 10^{-3} \mathrm{~km}^{2}$ (CV: 0.63). In 2006, 25 crab trawl hauls of approximately $16 \mathrm{~min}$ duration were conducted, covering on average $5.7 \times 10^{-3} \mathrm{~km}^{2}(\mathrm{CV}: 0.54)$. The abundance of crabs (ind. $\mathrm{km}^{-2}$ ) was estimated for each haul by dividing the number of crabs caught per crab trawl haul by the area covered by the individual haul (Table S1). Estimates of mean abundance (ind. $\mathrm{km}^{-2}$ ) in each stratum were calculated from abundance values of all crab trawl stations within the stratum (Table 2).

The correlation between king crab abundance (ind. $\mathrm{km}^{-2}$ ) and $E D$ was tested by calculating correlation coefficients $\left(\mathrm{r}_{\mathrm{S}}\right)$. ED was estimated from grab samples taken at the midpoint of each crab trawl track. The correlation between crab abundance and distance from the CSA to the midpoint of the trawl track was also tested. Finally, distance from CSA was divided into $2 \mathrm{~km}$ bins $(0-2,2-4,4-6$ and $>6 \mathrm{~km})$ to investigate whether red king crab abundance 
Table 2. Paralithodes camtschaticus abundance estimated from samples of trawl hauls by stratum, non-strata $\left(\mathrm{NS}_{\text {; }}\right.$ stations outside the stratified study area), and all hauls pooled (excluding NS), in 2005 and 2006. CV = $\mathrm{SD} / \mathrm{Mean}$

\begin{tabular}{|ccccrr|}
\hline Year & Strata & $\begin{array}{c}\text { Hauls } \\
(\mathrm{n})\end{array}$ & $\begin{array}{c}\text { Swept area } \\
\left(\mathrm{km}^{2}\right) \\
\text { Mean }(\mathrm{CV})\end{array}$ & $\begin{array}{c}\text { Depth } \\
(\mathrm{m}) \\
\text { Mean }(\mathrm{CV})\end{array}$ & $\begin{array}{r}\text { Red king crab } \\
\text { abundance } \\
\left(\text { ind. km }{ }^{-2}\right) \\
\text { Mean }(\mathrm{CV})\end{array}$ \\
\hline 2005 & S1 & 3 & $6.08 \times 10^{-3}(0.21)$ & $41.7(0.13)$ & $252(1.28)$ \\
& S2 & 6 & $7.72 \times 10^{-3}(0.16)$ & $81.7(0.34)$ & $3362(1.03)$ \\
& S3 & 2 & $1.75 \times 10^{-2}(0.74)$ & $147.0(0.16)$ & $433(1.41)$ \\
& S4 & 3 & $7.12 \times 10^{-3}(0.44)$ & $173.0(0.12)$ & $47(1.73)$ \\
2006 & S5 & 9 & $6.10 \times 10^{-3}(0.75)$ & $68.6(0.17)$ & $1099(0.87)$ \\
& S6 & 6 & $4.95 \times 10^{-3}(0.31)$ & $51.2(0.21)$ & $574(0.76)$ \\
& S7 & 4 & $5.91 \times 10^{-3}(0.51)$ & $67.3(0.10)$ & $230(1.16)$ \\
& NS & 6 & $5.50 \times 10^{-3}(0.27)$ & $126.3(0.32)$ & $349(1.66)$ \\
2005 & All & 14 & $8.63 \times 10^{-3}(0.63)$ & $102(0.53)$ & $1567(1.72)$ \\
& All & 25 & $5.65 \times 10^{-3}(0.54)$ & $78.2(0.45)$ & $654(1.13)$ \\
\hline
\end{tabular}

estimated within each stratum and as a total for each of the stratified areas examined in 2005 and 2006. Crabs were assumed to feed continuously, and consumption of eggs $(C)$ in an area (stratum of total stratified area) was estimated by the equation:

$$
C=\left(\frac{W}{A}\right) \times 24 \times T \times P
$$

where $W$ is the mean number of eggs found in the stomachs, $A$ is the average time (h) required to evacuate capelin eggs at $2.9^{\circ} \mathrm{C}, T$ is the time eggs are available for predation (d) and $P$ is the total number of red king crabs.

Uncertainty of input data was taken into account using the MC simulation approach described in Mikkelsen \& Ped-

changed non-monotonically with distance, and the Kruskal-Wallis test was used to examine whether red king crab abundance differed between bins.

\section{Stomach evacuation model}

An exponential decay model was fitted to the experimental data on the proportion of eggs remaining in the stomach $f(t)$ at the time ( $t$, in hours) after the start of feeding and is given by:

$$
f(t)=\mathrm{e}^{-b \times t}
$$

where $b$ is the decay constant. $f(t)$ was fitted to experimental data by nonlinear regression in SYSTAT, assuming a normal error distribution, and the model fit was evaluated by the significance of the model parameter, residual analysis and the adjusted $r^{2}$. Statistical outliers were defined as estimates with values more than 3 times the SD of the mean of residuals. The mean time $A(\mathrm{~h})$ to evacuate capelin eggs from the crab stomach was estimated according to Olson \& Boggs (1986) by integrating $f(t)$ numerically, using the equation:

$$
A=\int f(t) \mathrm{dt}
$$

The estimate of $A$ and its SE were used in the following estimation of consumption.

\section{Capelin egg consumption estimates}

A model approach described by Olson \& Boggs (1986) was applied to estimate the consumption of capelin eggs by red king crabs. Consumption was ersen (2012). Values for input data to MC were randomly selected from distributions expected to describe the uncertainty in the data (Table 3). The mean number of eggs in crab stomachs $(W)$ per stratum (S1 to S7) was calculated by generating 1000 bootstrap replicates of stomach content $(W)$ from the respective stratum. Thereafter, $W$ for each bootstrap replicate was implemented for each run of the $\mathrm{MC}$ simulation. Digestion time $(A)$ was implemented in $\mathrm{MC}$ runs by randomly selecting values from a normal distribution and the SD was set to the estimated SE.

Since the incubation time of fish eggs is related to temperature, a functional relationship for incubation time for capelin eggs as a function of temperature was fitted to previously published data (Gjøsæeter \& Gjøsæter 1986) using nonlinear regression. Gjøsæter \& Gjøsæter (1986) found that capelin eggs hatched after 59, 37 and $25 \mathrm{~d}$, at temperatures of 2,4 and $7^{\circ} \mathrm{C}$, respectively. The fitted model is described by the power equation:

$$
I_{t}=94.7 \times T_{m}^{-0.68}
$$

where $I_{t}$ is incubation time (d) for capelin eggs and $T_{m}$ is the temperature $\left({ }^{\circ} \mathrm{C}\right)$. To consider the temperature variability during the incubation time and measurement error, the minimum and maximum incubation times were calculated by adding $\pm 0.5^{\circ} \mathrm{C}$ to the average bottom temperature of $3.61^{\circ} \mathrm{C}$ measured in 2005 and $3.98^{\circ} \mathrm{C}$ measured in 2006 , from CTD measurements. The time period for which eggs are available for predation $(T)$ is implemented in the consumption model by random sampling for each MC run from a uniform distribution ranging from 36-44 d in 2005 and $34-40 \mathrm{~d}$ in 2006. 
Table 3. Input data for Monte Carlo simulations of consumption of capelin (Mallotus villosus) eggs by red king crabs Paralithodes camtschaticus at 2 capelin spawning sites in 2005 and 2006. Input data were randomly selected from distributions assumed to sufficiently describe uncertainty in the input data: mean stomach content ( $W$, no. of eggs), average stomach evacuation time $\left(A_{;} \mathrm{h}\right)$, egg incubation time $(T ; \mathrm{d})$ and red king crab abundance $\left(P_{i}\right.$ ind. $\left.\mathrm{km}^{-2}\right)$ by stratum in study areas

\begin{tabular}{|c|c|c|}
\hline $\begin{array}{l}\text { Para- } \\
\text { meter }\end{array}$ & Distribution & Source \\
\hline$W$ & 1000 values from empirical distribution & $\begin{array}{l}\text { Values were generated by bootstrapping replicates with } \\
\text { replacement of stomach content estimated from field data per stratum } \\
\text { (S1-S7) and all stomach data pooled for input by year. Number of } \\
\text { crab stomach data per stratum is listed. } \\
\text { S1 }(\mathrm{n}=3), \mathrm{S} 2(\mathrm{n}=88), \mathrm{S} 3(\mathrm{n}=33), \mathrm{S} 4(\mathrm{n}=1), 2005(\mathrm{n}=125) \\
\text { S5 }(\mathrm{n}=31), \mathrm{S} 6(\mathrm{n}=12), \mathrm{S} 7(\mathrm{n}=7), 2006(\mathrm{n}=50)\end{array}$ \\
\hline$A$ & $\mathrm{~A} \simeq \mathrm{N}(5.376 \pm 0.458)$ & $\begin{array}{l}A=\int f(t) \mathrm{d} t \text {, stomach evacuation function fitted to experimental data } \\
\text { in this study. Asymptotic SE (estimated in SYSTAT by FUNPAR) } \\
\text { was set to SD }\end{array}$ \\
\hline $\begin{array}{l}T_{2005} \\
T_{2006}\end{array}$ & $\begin{array}{l}\text { Uniform (min. }=36, \max .=44) \\
\text { Uniform (min. }=34, \max .=40)\end{array}$ & $\begin{array}{l}\text { Field observations (this study), incubation time model } I_{t} \text { (this study) } \\
\text { based on data from Gjøsæter \& Gjøsæter (1986) }\end{array}$ \\
\hline$P$ & 1000 values from empirical distribution & $\begin{array}{l}\text { Values were generated by bootstrapping replicates of abundance } \\
\text { (total number) estimated from trawl hauls per stratum (S1-S7) and all } \\
\text { trawl data pooled for input data by year. Number of trawl stations } \\
\text { per stratum is listed. } \\
\text { S1 }(n=3), S 2(n=6), S 3(n=2), S 4(n=3), 2005(n=14) \\
\text { S5 }(n=9), S 6(n=6), S 7(n=5), 2006(n=19)\end{array}$ \\
\hline
\end{tabular}

Input values for the number of red king crabs in each stratum were calculated by bootstrapping crab abundance data from the crab trawl hauls (Table S1), and 1000 bootstrap replicates of a total average number of crabs $(P)$ in each stratum were implemented in the MC runs following the same procedure as described for $W$.

Consumption estimates with their 95\% CIs were compared by strata and by year for the total stratified areas as the sum of values from each stratum. CI values were estimated by using the percentile method on the 1000 resamples. Furthermore, the influence of uncertainty in input parameters on the consumption estimates was evaluated by studying the correlation $\left(\mathrm{r}_{\mathrm{S}}\right)$ between the input values and MC estimates of consumption. Finally, egg consumption estimated by MC simulation was expressed as the proportion of egg numbers available in each year.

\section{RESULTS}

\section{Predation in the field}

The highest egg density estimate in 2005 was in Stratum S1, with a mean of $4.48 \times 10^{5}$ eggs $\mathrm{m}^{-2}$ (Fig. 2), while the highest recording in 1 grab was $8.71 \times 10^{6}$ eggs m$~^{-2}$. In 2005, Stratum 4 had the lowest mean egg density, with 19 eggs $\mathrm{m}^{-2}$, that all were found on the sieve when grab samples were processed. The substrate in the spawning areas was predominantly by pebble/shell gravel and a hard bottom (Table S1 in the Supplement at www.intres.com/articles/suppl/m563p139_supp.pdf). In 2006, the highest egg density recorded was in Stratum 6, with a mean of $2.10 \times 10^{4}$ eggs $\mathrm{m}^{-2}$ (Table 4 ). The highest record of eggs in one grab sample was $4.88 \times$ $10^{5}$ eggs $\mathrm{m}^{-2}$. In 2006, some eggs were at hatching stage during grab sampling. When measured by CL,

Table 4. Estimated mean densities of capelin (Mallotus villosus) eggs in study areas in 2005 and 2006 by stratum and the total stratified area (SA). Estimates of mean, SD, high and low $95 \%$ CI are calculated by Monte Carlo simulation by bootstrapping input data from grab samples from Survey II.

The means by year are given for the stratified areas

\begin{tabular}{|cccccc|}
\hline \multirow{2}{*}{ Year } & \multirow{2}{*}{$\begin{array}{c}\text { Stra- } \\
\text { tum }\end{array}$} & \multicolumn{5}{c}{ Mean } & SD density & (eggs m $\left.^{-2}\right)$ & CI low & CI high \\
\hline 2005 & S1 & $4.48 \times 10^{5}$ & $3.79 \times 10^{5}$ & $1.78 \times 10^{4}$ & $1.26 \times 10^{6}$ \\
& S2 & $1.65 \times 10^{3}$ & $1.33 \times 10^{3}$ & $1.17 \times 10^{2}$ & $4.37 \times 10^{3}$ \\
& S3 & $5.89 \times 10^{2}$ & $3.02 \times 10^{2}$ & $1.50 \times 10^{2}$ & $1.00 \times 10^{3}$ \\
& S4 & $1.90 \times 10^{1}$ & $1.19 \times 10^{1}$ & 2.86 & $4.71 \times 10^{1}$ \\
2006 & S5 & $2.19 \times 10^{1}$ & $1.17 \times 10^{1}$ & 4.00 & $4.85 \times 10^{1}$ \\
& S6 & $2.10 \times 10^{4}$ & $1.23 \times 10^{4}$ & $7.02 \times 10^{1}$ & $4.76 \times 10^{4}$ \\
& S7 & $8.22 \times 10^{1}$ & $5.52 \times 10^{1}$ & 6.67 & $1.95 \times 10^{2}$ \\
2005 & SA & $2.57 \times 10^{4}$ & $2.10 \times 10^{4}$ & $1.42 \times 10^{3}$ & $7.06 \times 10^{4}$ \\
2006 & SA & $7.29 \times 10^{3}$ & $4.26 \times 10^{3}$ & $5.56 \times 10^{1}$ & $1.65 \times 10^{4}$ \\
& & & & & \\
\hline
\end{tabular}




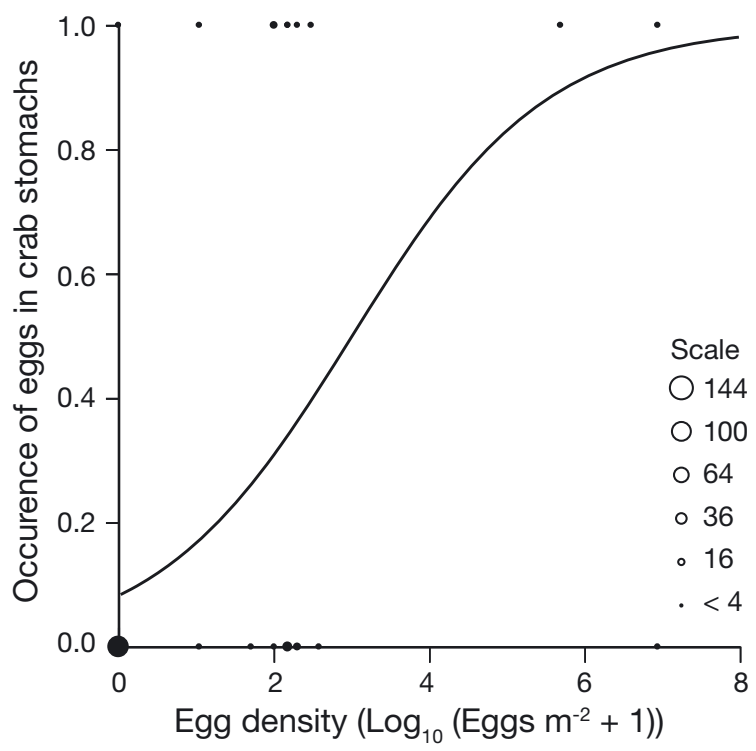

Fig. 4. Occurrence of capelin (Mallotus villosus) eggs in red king crab (Paralithodes camtschaticus) stomachs with increasing egg densities (ED) as independent variable. Observed data are illustrated by markers and the fitted logistic model $P(x)$ is illustrated by the line. Size of markers indicates the number of stomachs:

$$
P(x)=\frac{1}{\left(1+\mathrm{e}^{-2.39+0.80 \times E D}\right)}
$$

red king crabs in samples from 2006 (mean CL: $152 \mathrm{~mm}$ ) were significantly larger than crabs sampled in 2005 (mean CL: $125 \mathrm{~mm}$ ) ( $t$-test, $t=-9.45, \mathrm{df}=118$ and $\mathrm{p}<0.001)$. No dead post-spawn capelin were found in grab samples.

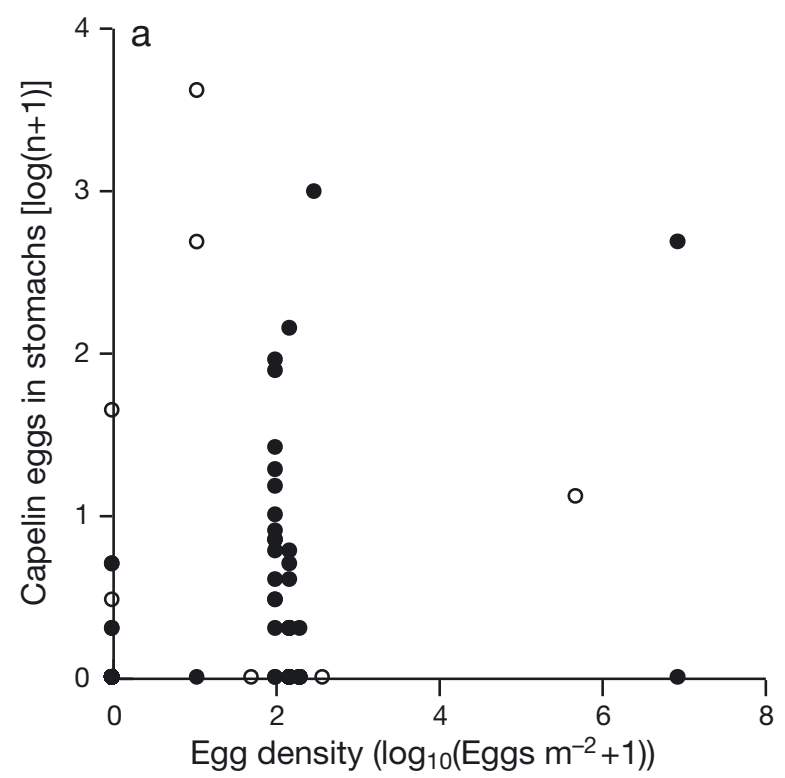

Capelin eggs were found in $23.2 \%$ and $10.0 \%$ of all analysed crabs, in 2005 and 2006, respectively. Capelin were identified more frequently in crab stomachs than capelin eggs during both years, with $81.6 \%$ and $21.7 \%$ for 2005 and 2006, respectively (Table S1). The occurrence of capelin eggs in crab stomachs was found to increase with increasing egg density $(p<0.001)$ according to logistic regression analysis of $g(x)$, when all other effects were removed (Fig. 4; Table S5 in the Supplement). The likelihood ratio test indicated that the model was highly significant (chi-squared test, $\chi^{2}=26.61, \mathrm{df}=1, \mathrm{p}<0.01$ ) when only $E D$ was included (Fig. 4), and successfully predicted $31 \%$ of the occurrences of eggs, and $84 \%$ of absences of eggs in crab stomachs (Table S5). For egg-feeding crabs, the correlation between the number of eggs in individual crab stomachs and egg density was not significant $\left(2005: \mathrm{r}_{\mathrm{S}}=-0.04, \mathrm{p}>0.05, \mathrm{n}=\right.$ 29; 2006: $r_{S}=0.49, p>0.05, n=6$ ) (Fig. 5a), nor with distance from the CSA $\left(2005: \mathrm{r}_{\mathrm{S}}=-0.32, \mathrm{p}>0.05, \mathrm{n}=\right.$ 29; 2006: $r_{S}=-0.35, p>0.05, n=6$ ) (Fig. 5b). It cannot be excluded that there could be a relationship between capelin egg density and eggs per crab stomach or crab density at a finer scale than was resolved by the trawl sampling of crabs over a distance of typically $1 \mathrm{~km}$.

Crab abundance in Stratum S1, which had the highest capelin egg density and where the CSA was positioned, was lower (mean: 252 ind. $\mathrm{km}^{-2}, \mathrm{CV}: 1.28$ ) than in S2 (mean: 3362 ind. $\mathrm{km}^{-2}, \mathrm{CV}: 1.03$ ), which surrounds S1 (Fig. 2, Table 2), but the difference in

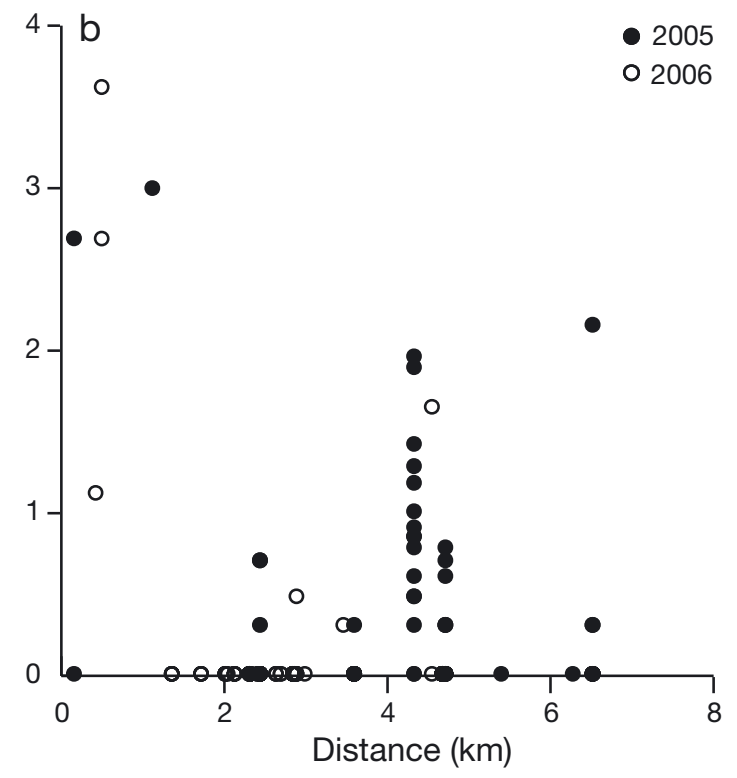

Fig. 5. Number of capelin (Mallotus villosus) eggs in red king crab (Paralithodes camtschaticus) stomachs $\left(\mathrm{n}_{2005}=125\right.$, $\mathrm{n}_{2006}=60$ ) plotted against (a) egg density and (b) distance from centre of spawning area 

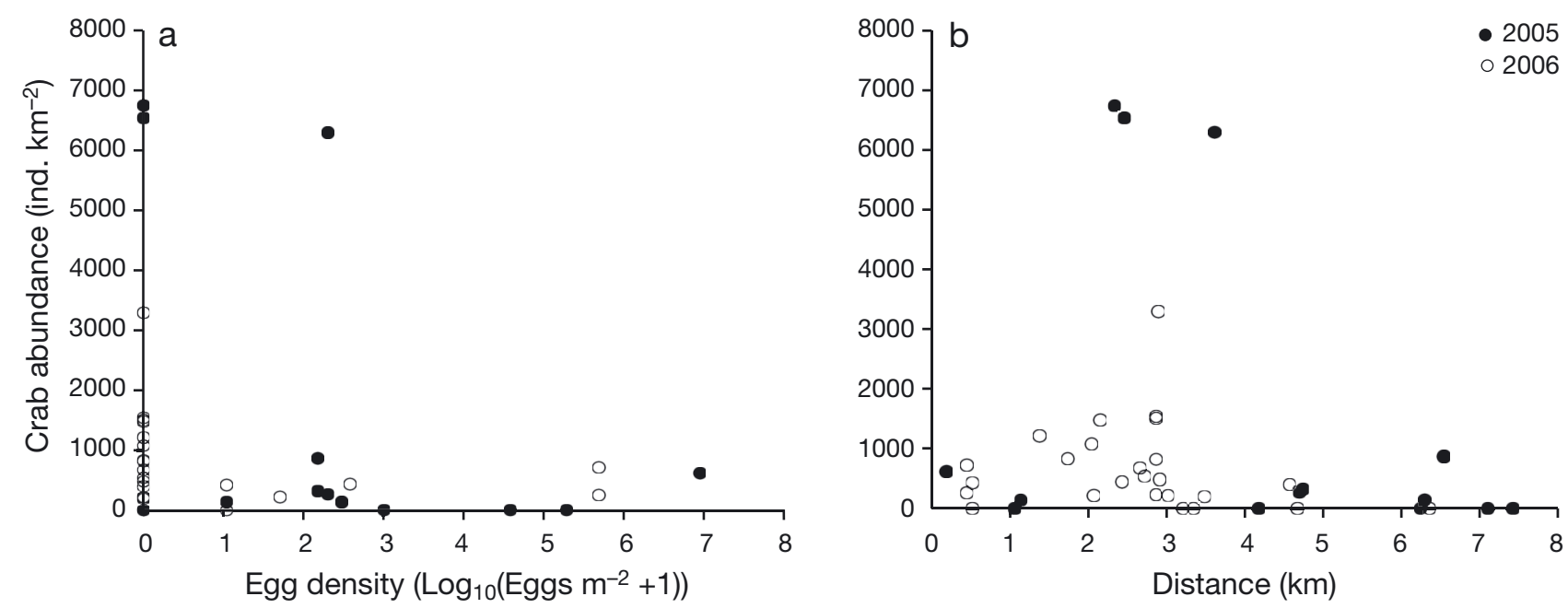

Fig. 6. Abundance of red king crab Paralithodes camtschaticus with respect to (a) density of capelin (Mallotus villosus) eggs and (b) distance from centre of spawning area

abundance was not significant (Mann-Whitney $U=$ $4.50, \mathrm{p}>0.05)$. In 2005, the lowest crab abundance (47 ind. $\mathrm{km}^{-2}$ ) was found in S4, which was located the furthest from the CSA. The highest crab abundance in 2006 was estimated as 1099 ind. $\mathrm{km}^{-2}$ in Stratum 5 (Table 2).

Crab abundance and egg density were not significantly correlated in either of the 2 study years (2005: $\mathrm{r}_{\mathrm{S}}=-0.26, \mathrm{p}>0.05, \mathrm{n}=14 ; 2006: \mathrm{r}_{\mathrm{S}}=-0.16, \mathrm{p}>0.05$, $\mathrm{n}=25$ ) (Fig. 6a), and the abundance of crabs was not significantly correlated to distance from the CSA (2005: $\mathrm{r}_{\mathrm{S}}=-0.35, \mathrm{p}>0.05, \mathrm{n}=14 ; 2006: \mathrm{r}_{\mathrm{S}}=-0.36$,

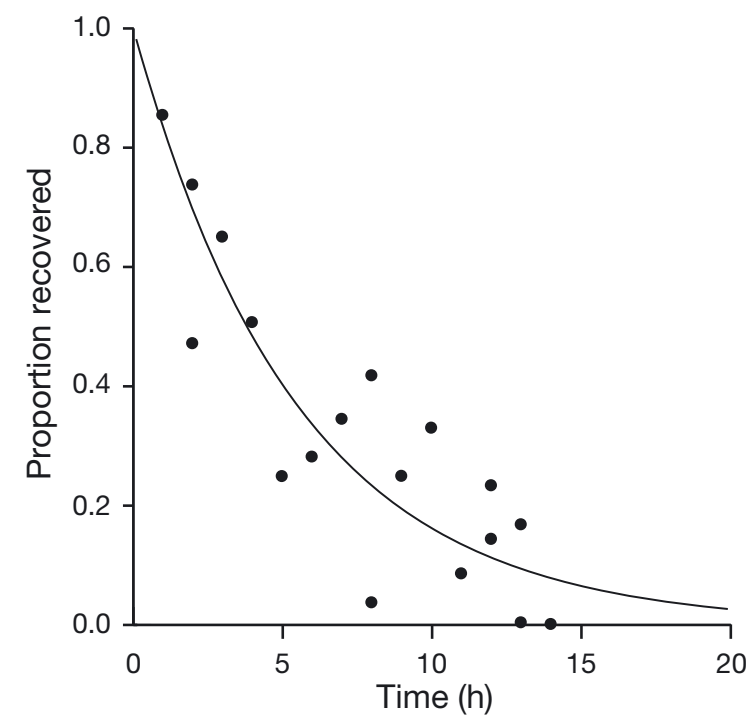

Fig. 7. Stomach evacuation rate of red king crabs Paralithodes camtschaticus fed capelin (Mallotus villosus) eggs at $3^{\circ} \mathrm{C}$. Observed proportions of eggs left in stomachs at a given time are illustrated by data points. Line shows the exponential decay function $f(t)$ fitted by nonlinear regression:

$$
f(t)=\mathrm{e}^{-0.182 \times t}
$$

$\mathrm{p}>0.05, \mathrm{n}=25$ ) (Fig. 6b). When distance was categorised into 4 groups, the apparent pattern towards higher density of crabs at a distance of $2-4 \mathrm{~km}$ from CSA (Fig. 6b) was not significant at $\alpha=0.05$ (KruskalWallis tests: 2005: $\chi^{2}=7.25, \mathrm{df}=3, \mathrm{p}=0.06 ; 2006$ : $\chi^{2}=3.63, \mathrm{df}=3, \mathrm{p}=0.31$ ).

\section{Stomach evacuation experiment}

The acclimatisation period of crabs was short in this study, because of delays in the collection of experimental animals. However, crabs began feeding within hours after arrival, indicating that a short acclimation period of red king crabs may be sufficient in similar future experiments. On average, the crabs consumed $0.53 \%$ of their BW in the experiment, and $45.5 \%$ of the eggs offered (by weight) were not consumed (Table S4 in the Supplement).

The parameter $b$ in the stomach evacuation model $f(t)$ was estimated at $0.18 \mathrm{~h}^{-1}(95 \%$ CI: $0.15-0.22)$, and the adjusted $r^{2}$ was 0.78 (Fig. 7). There were no statistical outliers detected, the residuals were normally distributed (Lilliefors test, $\mathrm{p}=0.12$ ), and the variance was homogeneous (chi-squared test, $\chi^{2}=$ $13.52, \mathrm{df}=17, \mathrm{p}=0.60)$. The average time $(A)$ required to evacuate capelin eggs from red king crab stomachs at $2.9^{\circ} \mathrm{C}$ was estimated at $5.38 \mathrm{~h}(95 \% \mathrm{CI}$ : 4.41-6.34).

\section{Consumption estimates}

The total consumption of capelin eggs by red king crabs at the 2 selected spawning sites in 2005 and 
Table 5. Total number of capelin (Mallotus villosus) eggs (E), and their consumption $(C)$ by red king crabs Paralithodes camtschaticus estimated by Monte Carlo simulation for each stratum and the stratified area (SA) by year. $\mathrm{CV}=\mathrm{SD} / \mathrm{Mean}$

\begin{tabular}{|ccccc|}
\hline Year & $\begin{array}{c}\text { Stra- } \\
\text { tum }\end{array}$ & $\begin{array}{c}E \text { : capelin eggs (n) } \\
\text { Mean (CV) }\end{array}$ & $\begin{array}{c}C \text { : consumption (n) } \\
\text { Mean }(C V)\end{array}$ & $\begin{array}{c}C / E(\%) \\
\text { Mean (CV) }\end{array}$ \\
\hline 2005 & S1 & $3.40 \times 10^{12}(0.85)$ & $2.09 \times 10^{8}(0.85)$ & $0.04(8.21)$ \\
& S2 & $9.99 \times 10^{10}(0.81)$ & $8.08 \times 10^{7}(1.11)$ & $0.27(2.22)$ \\
& S3 & $8.94 \times 10^{9}(0.51)$ & $1.35 \times 10^{7}(1.34)$ & $0.26(1.88)$ \\
& S4 & $1.01 \times 10^{9}(0.63)$ & 0 & \\
2006 & S5 & $1.56 \times 10^{8}(0.82)$ & 0 & $5.39(7.19)$ \\
& S6 & $1.68 \times 10^{11}(0.53)$ & $4.86 \times 10^{8}(1.17)$ & $0.02(2.18)$ \\
& S7 & $6.59 \times 10^{8}(0.59)$ & $6.12 \times 10^{4}(1.11)$ & $0.03(2.08)$ \\
2005 & SA & $3.51 \times 10^{12}(0.67)$ & $3.06 \times 10^{8}(0.65)$ & $2.23(6.40)$ \\
2006 & SA & $1.68 \times 10^{11}(0.58)$ & $4.14 \times 10^{8}(1.33)$ & $2.23)$ \\
\hline
\end{tabular}

eggs are available added less uncertainty to the consumption estimates (Table 6).

The average number of eggs per stomach was approximately 19 times higher in 2006 than in 2005 (Table S6 in the Supplement), while the numbers of red king crabs in the study areas in 2005 and 2006 were estimated at 216994 and 14157 individuals, respectively. The highest value for the proportion of eggs consumed per eggs available was in Stratum 6 in 2006 (Table 5), where approximately $5.39 \%$ of all capelin eggs available were consumed by red king crabs. The corresponding proportion for the whole study area in 2006 was $2.23 \%$. In 2005, consumption of eggs in S1 was 2006 were estimated to be $3.06 \times 10^{8}$ and $4.14 \times 10^{8}$ eggs, respectively (Table 5). The estimated consumption by stratum was highest in S6, but this estimate also had the widest high CIs. This led to an upper $95 \%$ confidence level that was 3.6 times the mean estimate (Table 5). The mean number of eggs in crab stomachs was highly variable, ranging from 0-2283 (Table S1), which resulted in considerable uncertainty in the consumption estimates. Input values to MC simulations for the average number of eggs found in stomachs and estimated consumption values were strongly correlated (Table 6). The uncertainty of input data for the total number of red king crab in the sample areas also influenced consumption estimates, while uncertainty in digestion time and time

Table 6. Spearman rank correlation coefficient $\left(\mathrm{r}_{\mathrm{S}}\right)$ between model output $C$, consumption estimates of capelin (Mallotus villosus) eggs, and input data to the consumption model for $W$, average number of eggs in stomach (n); $A$, average digestion time $(\mathrm{h}) ; T$, time eggs are available $(\mathrm{d})$; and $P$, number of red king crabs Paralithodes camtschaticus in strata $\mathrm{S} 1-\mathrm{S} 7$ and in stratified area (SA) by year. $\mathrm{r}_{\mathrm{S}}$ was calculated from 1000 bootstrap resamples from the Monte Carlo simulation. -: no data

\begin{tabular}{|lccccc|}
\hline Year & Stratum & $W$ & $A$ & $T$ & $P$ \\
\hline 2005 & S1 & 0.56 & -0.13 & 0.01 & 0.73 \\
& S2 & 0.92 & -0.04 & 0.05 & 0.30 \\
& S3 & 0.61 & -0.02 & 0.07 & 0.74 \\
& S4 & - & - & - & - \\
2006 & S5 & - & - & - & - \\
& S6 & 0.93 & -0.07 & 0.04 & 0.27 \\
& S7 & 0.84 & -0.05 & 0.03 & 0.49 \\
2005 & SA & 0.80 & -0.15 & 0.07 & 0.22 \\
2006 & SA & 0.99 & -0.11 & -0.01 & 0.20 \\
\hline
\end{tabular}

relatively high in terms of number, but this stratum also had the highest egg density, which led to a lower value for the proportion of eggs consumed $(0.04 \%)$ (Table 5).

\section{DISCUSSION}

\section{Predation in the field}

This study confirms that invasive red king crab fed on both capelin eggs and capelin off the coast of Finnmark, Norway. Capelin was found in $81.6 \%$ and $21.7 \%$ of the analysed red king crab stomachs in 2005 and 2006, respectively, while capelin eggs were found in $23.2 \%$ and $10.0 \%$ of crabs in 2005 and 2006, respectively. These results are in accordance with a previous study where $19 \%$ of analysed red king crab stomachs were reported to contain capelin eggs (Anisimova et al. 2005). However, as some capelin eggs were hatching at the time of the survey in 2006, it is possible that egg density and the occurrence of eggs in crab stomachs were underestimated during that year.

The occurrence of egg predation by the red king crab was related to capelin egg density, when predicted by logistic models. Neither distance from the CSA, year, or crab size contributed significantly to the egg occurrence in crab stomachs, even though the crabs sampled in 2006 were significantly larger than crabs sampled in 2005. The lack of a crab size effect in our study may be explained by the relatively narrow size composition of our sample and that the crabs were not concentrating on feeding on capelin eggs. Juvenile crabs are commonly distributed in shallower and more sheltered areas (Pavlova 2008, 
Jørgensen \& Nilssen 2011) than those used as spawning sites by Barents Sea capelin (Sætre \& Gjøsæter 1975).

For crabs with egg(s) in the stomach, the number of eggs in stomachs and egg density were not significantly correlated, indicating no strong relationship between the number of eggs eaten and egg density. The observation in the experiment where the red king crab was found to be an inefficient capelin egg feeder supports the lack of relationship between individual egg consumption and egg density. The generalist feeding behaviour of the red king crab may explain this (Falk-Petersen et al. 2011), as crabs may be 'testing and tasting' many different prey taxa, which can result in an increase in the proportion of crabs consuming eggs with increasing egg density, although the amount ingested may not necessarily increase. Capelin eggs, which adhere to the substrate, can also be ingested accidentally when the crab feeds on other organisms at spawning sites. Substrate is often found in the stomachs of crabs, as they sometimes scoop substrate while searching for food (Jørgensen 2005). Such 'incidental' feeding on eggs would also increase the occurrence of eggs in the crab's stomach at high egg densities; however, the amount of eggs eaten would not increase in the same manner if eggs were not actively sought as prey. Furthermore, as some capelin are egg cannibals (Slotte et al. 2006) and the red king crab feeds on capelin, some eggs could be secondary prey.

Because some crabs were able to eat high amounts of capelin, eggs even at low egg densities and at distances of up to approximately $6 \mathrm{~km}$ from high egg density areas suggests some individual specialisation in feeding behaviour. These findings support the results of a previous study of crabs feeding on lumpsucker eggs, where the crabs displayed different feeding behaviour and were apparently specialised (Mikkelsen \& Pedersen 2012). Such specialisation in invasive species may affect prey populations (Bolnick et al. 2003), even though the red king crab is often described as an opportunistic generalist feeder (Jewett \& Feder 1982, Jørgensen \& Primicerio 2007), which is the most common feeding behaviour among crustacean invaders (Hanfling et al. 2011).

The more frequent occurrence of capelin in crab stomachs than capelin eggs indicates that spent capelin is more important as a food source for crabs than capelin eggs. Given a gonadosomatic index of $27.1 \%$ for female capelin just before spawning (Christiansen et al. 2008), the amount of spent capelin available by weight is much larger than the amount of capelin eggs. Hence, if most crabs have an opportunistic feeding behaviour, this would explain the higher occurrence of capelin rather than capelin eggs in crab stomach in this study.

In 2005, capelin occurred more frequently in crab stomachs than in 2006, and this may be a consequence of reduced availability of capelin as prey for crab in 2006. Because some eggs were observed to be hatching during sampling in 2006, this suggests that spawning had occurred somewhat earlier that year and that dead post-spawned capelin on the seabed already had been consumed by crabs or other predators. Also, the study area in 2006 was smaller than in 2005, as were the density of egg and crabs.

The death of Barents Sea capelin after spawning supplies a high abundance of alternative prey for predators and may contribute to the low predation pressure on their demersal eggs by predator swamping. Such saturation of predators has been observed previously in fish (Kempf et al. 2008) and ctenophores (Majaneva et al. 2013). In Canadian waters, sea urchins Strongylocentrotus droebachiensis aggregate around dead capelin, but not at spawning beds with high capelin egg density (Crook \& Davoren 2016). Assuming that dead capelin release more odour than capelin eggs, and because prey odour is considered to be an essential factor for foraging in red king crabs, these crabs may be attracted to dead capelin by olfactory stimuli (Zhou \& Shirley 1997), just as crabs are efficiently attracted to bait in pot fisheries (Stiansen et al. 2010). Because the invasive red king crab feeds on dead post-spawned capelin on the seabed, native haddock may compete with the red king crab for capelin, which is the most important prey for haddock during the spring season (Bogetveit et al. 2008). As haddock may feed on both dead post-spawn capelin and capelin eggs (Huse \& Toresen 1996, Gjøsæeter 1998), we speculate that this competition may indirectly enhance egg predation by haddock.

The lack of aggregation of crabs in areas with high capelin egg density in 2005 and 2006 indicates that there is no aggregative response by red king crab to capelin egg density. However, a slight trend towards higher crab abundance was observed $2-4 \mathrm{~km}$ from the CSA, although this correlation was not significant. We speculate that the increased abundance of crabs near spawning sites could be related to crabs feeding on dead post-spawn capelin on the seabed serving as alternative prey. Our estimate of maximum crab abundance (both sexes included) of about 3362 ind. $\mathrm{km}^{-2}$ is slightly lower than the abundance estimates from high-density areas in Russian waters of the Barents Sea in 2003, when crab abundance was at its maximum. The Russian average abun- 
dance estimate of commercial sized males $(>132 \mathrm{~mm}$ CL) was 1873 ind. $\mathrm{km}^{-2}$ in the high-density areas (Anisimova \& Manushin 2008), which suggests that red king crab abundance was relatively high at capelin spawning sites in 2005. It is possible that red king crabs show some aggregation towards capelin spawning areas on a coarser scale than analysed in this paper, as we observed lower density of crabs on the spawning area for 2005 when the area was surveyed in 2006 (unpubl. results).

\section{Stomach evacuation rate}

The exponential decay model describing the stomach evacuation rate of capelin eggs in red king crab stomachs fitted the experimental data well. This model has been considered appropriate for estimating evacuation of relatively easily digested particles from fish stomachs (Jobling 1986). This model has also been applied and fitted to experimental data for another crustacean species, Nephrops norvegicus (Cristo 2001). The estimated average stomach evacuation time in our study of $5.38 \mathrm{~h}$ at $2.9^{\circ} \mathrm{C}$ is lower than the $9.97 \mathrm{~h}$ estimated for lumpsucker eggs at $6^{\circ} \mathrm{C}$ (Mikkelsen \& Pedersen 2012). This result is plausible because lumpsucker eggs have a thicker egg chorion and are approximately twice the size of capelin eggs, when egg diameter is used as the parameter (Lønning et al. 1988).

Red king crabs had the same feeding techniques when feeding on capelin eggs in the current study as they did on lumpsucker eggs in a previous study (Mikkelsen \& Pedersen 2012), but the proportion of unconsumed eggs $(45.5 \%)$ in the present study was considerably higher than that for crabs feeding on lumpfish eggs $(8.4 \%)$. Capelin eggs are not glued together as hard as lumpsucker eggs are (N. Mikkelsen unpubl. data), and when the clumps of eggs were lost to the bottom during feeding, the crabs did not succeed in picking up the egg clumps again. The proportion of unconsumed eggs may have been enhanced by the nature of the experimental tanks, which had a slope that slightly declined towards the centre of the tank, resulting in movement of the eggs to the centre of the tank. The crabs also disrupted the rectangular clumps of eggs, making it difficult for crabs to pick up the resulting small clumps and individual eggs from the bottom of the tank. When feeding on natural sediment substrate, crabs grasp items more easily than in the experimental tanks, and this potentially reduces the proportion of unconsumed eggs in nature. In this experiment, we decided to avoid stressing the experimental animals by substantial cleaning of substrate, which would have been the case if we were to supply capelin eggs mixed into substrate as in nature.

The acclimatisation period of crabs, from collection in the field until the start of the experiment, was shorter in this study than in similar studies, because poor weather conditions caused delays in the collection of experimental animals. However, the experimental crabs became calm shortly after arrival and began feeding within hours, indicating that the durations of the acclimation periods were sufficient and should be considered in similar future experiments.

\section{Capelin egg consumption estimates}

The estimated egg consumption values of the red king crab of $0.03 \%$ and $2.23 \%$ of total capelin egg numbers present at spawning sites in 2005 and 2006 were similar to those estimated $(0.03 \%)$ by Anisimova et al. (2005) for Barents Sea capelin in 2001. This implies that the red king crab may influence capelin egg mortality by feeding, but that the impact is unlikely to hamper recruitment of the Barents Sea capelin. However, the total egg loss is probably higher than the consumption estimates because of damage to eggs during feeding. In support of this, damage of prey that leads to higher mortality than that resulting from consumption alone has also been reported in experimental studies (Jørgensen 2005, Pavlova 2009, Michelsen 2011).

Even though the occurrence of capelin eggs in crab stomachs in the stratified study area was more frequent in 2005 than in 2006, the estimated consumption was lower in 2005, because the mean number of eggs in crab stomachs in 2006 was higher than in 2005. However, the number of eggs in crab stomachs was highly variable and the variability was a major contributor to the uncertainty in the consumption estimates. Uncertainty in the input data for crab abundance also contributed to uncertainty in the consumption estimates in both the present and in the previous study of lumpsucker egg consumption by red king crabs (Mikkelsen \& Pedersen 2012). The strong correlation between stomach data and consumption estimates suggests that uncertainty in consumption estimates could be reduced in future studies of red king crab consumption if more effort was allocated to stomach analysis.

In Norwegian waters, the stock abundance of red king crab peaked in 2008, followed by a decline thereafter. However, the crab is still expanding its 
distribution in Norwegian waters west and southwards (Windsland et al. 2014), overlapping spatially with more capelin spawning grounds (Gjøsæter 1998). After 2006, capelin abundance appeared not to respond negatively to the range expansion of red king crab, and capelin recruitment has been good, but variable from 2007 to 2014 (ICES 2016).

\section{Conclusions and implications}

Red king crabs feed on both capelin eggs and capelin, with capelin being more frequently found in crab stomachs. The amount of eggs found in eggfeeding crabs was not related to capelin egg density, but the occurrence of capelin eggs increased with increasing egg density. Red king crabs did not show an aggregative response to capelin egg density. The maximum estimated consumption of capelin eggs by red king crabs constituted $<2.5 \%$ of the eggs available, but total egg loss was higher because crabs damage uneaten eggs during feeding activity and may cause eggs to drift away from spawning sites. The semelparous life-history strategy of capelins can promote predator swamping and relax the predation on their eggs by the red king crab, as the crab is capable of feeding on both capelin and capelin eggs. When implementing an ecosystem approach in the management of Barents Sea capelin, the ecological value of spent and dead capelin should be considered (ICES 2011). Another predator feeding on dead post-spawn capelin on the seabed is the haddock Melanogrammus aeglefinus (Bogetveit et al. 2008), which may experience increased competition for this prey from the invasive red king crab.

Acknowledgements. We thank the Hans Christian Strand at the Institute of Marine Research for collecting crabs for experimental work, Ivan Ahlquist for fieldwork, Espen Rafter at Polaria for temporary storage of crabs, the North Capelin fish plant in Honnigsvåg and the HiT Aquaculture Research Station, Kårvika for research facilities, and the crew of R/V 'Johan Ruud'; and from UIT - the Arctic University of Norway: Trond Ivarjord for field and experimental work, Berit Bendiksen for fieldwork, Helge Meissner and Fredrikke Musæus for egg counting, and Emma Källgren for stomach analysis.

\section{LITERATURE CITED}

Anisimova N, Manushin I (2008) Benthos as prey for red king crab. In: Sundet JH, Berenboim B (eds) Research on the red king crab (Paralithodes camtschaticus) from the Barents Sea in 2005-2007. IMR/PINRO Joint Rep Ser 3/2008. Institute of Marine Research, Bergen, p 32-36
Anisimova N, Berenboim B, Gerasimova O, Manushin I, Pinchukov M (2005) On the effect of red king crab on some components of the Barents Sea ecosystem. In: Shibanov V (ed) Ecosystem dynamics and optimal longterm harvest in the Barents Sea fisheries. Proc 11th RussNorw Symp, Murmansk, 15-17 Aug. IMR/PINRO Joint Rep Ser 2/2005. PINRO Press, Bergen, p 298-306

* Bailey KM, Houde ED (1989) Predation on eggs and larvae of marine fishes and the recruitment problem. Adv Mar Biol 25:1-83

Bakke S, Bjørke H (1973) Diving observations on Barents Sea capelin at the spawning grounds off northern Norway. Fiskeridir Skr (Havunders) 16:140-147

Bax NJ (1998) The significance and prediction of predation in marine fisheries. ICES J Mar Sci 55:997-1030

Bogetveit FR, Slotte A, Johannessen A (2008) The ability of gadoids to take advantage of a short-term high availability of forage fish: the example of spawning aggregations in Barents Sea capelin. J Fish Biol 72:1427-1449

* Bogstad B, Gjøsæter H (2001) Predation by cod (Gadus morhua) on capelin (Mallotus villosus) in the Barents Sea: implications for capelin stock assessment. Fish Res 53:197-209

Bolnick DI, Svanback R, Fordyce JA, Yang LH, Davis JM, Hulsey CD, Forister ML (2003) The ecology of individuals: incidence and implications of individual specialization. Am Nat 161:1-28

Britayev TA, Rzhavsky AV, Pavlova LV, Dvoretskij AG (2010) Studies on impact of the alien red king crab (Paralithodes camtschaticus) on the shallow water benthic communities of the Barents Sea. J Appl Ichthyol 26: 66-73

Bunn NA, Fox CJ, Webb T (2000) A literature review of studies on fish egg mortality: implications for the estimation of spawning stock biomass by the annual egg production method. Sci Ser Tech Rep 111. Centre for Environment, Fisheries and Aquaculture Science, Lowestoft

Carscadden JE, Vilhjalmsson H (2002) Capelin - What are they good for? Introduction. ICES J Mar Sci 59:863-869

* Christiansen JS, Praebel K, Siikavuopio SI, Carscadden JE (2008) Facultative semelparity in capelin Mallotus villosus (Osmeridae) - an experimental test of a life history phenomenon in a sub-arctic fish. J Exp Mar Biol Ecol 360:47-55

Cristo M (2001) Gut evacuation rates in Nephrops norvegicus (L., 1758): laboratory and field estimates. Sci Mar 65: 341-346

Cristo M, Castro M (2005) Field estimation of daily ration of Norway lobster (Nephrops norvegicus) in the south of Portugal. N Z J Mar Freshw Res 39:485-491

Crook KA, Davoren GK (2016) Influence of spawning capelin Mallotus villosus on the distribution of green sea urchins Strongylocentrotus droebachiensis on the northeast Newfoundland coast. Mar Ecol Prog Ser 549: 125-135

Dahlberg MD (1979) Review of survival rates of fish eggs and larvae in relation to impact assessments. Mar Fish Rev 41:1-12

DeBlois E, Leggett WC (1991) Functional response and potential impact of invertebrate predators on benthic fish eggs: analysis of the Calliopius laeviusculus-capelin (Mallotus villosus) predator-prey system. Mar Ecol Prog Ser 69:205-216

DeBlois E, Leggett WC (1993a) Impact of amphipod predation on the benthic eggs of marine fish: an analysis of 
Calliopius laeviusculus bioenergetic demands and predation on eggs of a beach spawning Osmeriid (Mallotus villosus). Mar Ecol Prog Ser 93:205-216

DeBlois E, Leggett WC (1993b) Match/mismatch between the abundance of marine fish eggs and invertebrate predators: an analysis of Calliopius laeviusculus (Amphipoda: Gammaridae) population growth relative to the seasonal spawning cycle of capelin (Mallotus villosus). Can J Fish Aquat Sci 50:2581-2590

Dolgov AV (2002) The role of capelin (Mallotus villosus) in the foodweb of the Barents Sea. ICES J Mar Sci 59: 1034-1045

Donaldson WE, Byersdorfer SE (2005) Biological field techniques for Lithodid crabs. Alaska Sea Grant College Program, University of Alaska, Fairbanks, AK

Dragesund O, Nakken O (1973) Relationship of parent stock size and year class strength in Norwegian spring spawning herring. In: Parrish B (ed) Fish stocks and recruitment. Rapp P-V Réun Cons Perm Int Explor Mer 164: 15-29

Falk-Petersen J, Renaud P, Anisimova N (2011) Establishment and ecosystem effects of the alien invasive red king crab (Paralithodes camtschaticus) in the Barents Seaa review. ICES J Mar Sci 68:479-488

Feder HM, Paul AJ (1980) Food of the king crab (Paralithodes camtschatica) and the dungeness crab (Cancer magister) in Cook Inlet, Alaska. Proc Natl Shellfish Assoc 70:240-246

Francis R (1984) An adaptive strategy for stratified random trawl surveys. N Z J Mar Freshw Res 18:59-71

Frank KT, Leggett WC (1981) Prediction of egg development and mortality rates in capelin (Mallotus villosus) from meteorological, hydrographic, and biological factors. Can J Fish Aquat Sci 38:1327-1338

Frank KT, Leggett WC (1984) Selective exploitation of capelin (Mallotus villosus) eggs by winter flounder (Pseudopleuronectes americanus): capelin egg mortality rates, and contribution of eggs energy to the annual growth of flounder. Can J Fish Aquat Sci 41:1294-1302

Fridgeirsson E (1976) Observations on spawning behaviour and embryonic development of the Icelandic capelin. Rit Fiskideildar 5:1-35

Gjøsæter H (1998) The population biology and exploitation of capelin (Mallotus villosus) in the Barents Sea. Sarsia 83:453-496

Gjøsæter H, Bogstad B (1998) Effects of the presence of herring (Clupea harengus) on the stock-recruitment relationship of Barents Sea capelin (Mallotus villosus). Fish Res 38:57-71

Gjøsæter H, Gjøsæter J (1986) Observations on the embryonic development of capelin (Mallotus villosus Müller) from the Barents Sea. Fiskeridir Skr (Havunders) 18:59-68

Gjøsæter H, Bogstad B, Tjelmeland S (2009) Ecosystem effects of the three capelin stock collapses in the Barents Sea. Mar Biol Res 5:40-53

* Godiksen JA, Hallfredsson EH, Pedersen T (2006) Effects of alternative prey on predation intensity from herring Clupea harengus and sand-eel Ammodytes marinus on capelin Mallotus villosus larvae in the Barents Sea. J Fish Biol 69:1807-1823

* Gudimov AV, Gudimova EN, Pavlova LV (2003) Effect of the red king crab Paralithodes camtschaticus on the Murmansk coastal macrobentos: the first estimates using sea urchins of the genus Strongylocentrotus as an example. Dokl Biol Sci 393:539-541
Hallfredsson EH, Pedersen T (2007) Effects of predation from pelagic 0-group cod (Gadus morhua) on mortality rates of capelin (Mallotus villosus) larvae in the Barents Sea. Can J Fish Aquat Sci 64:1710-1722

*Hanfling B, Edwards F, Gherardi F (2011) Invasive alien Crustacea: dispersal, establishment, impact and control. BioControl 56:573-595

Haugan TA (2004) Bunnsamfunn og næringsvalg hos kongekrabbe, Paralithodes camtschaticus (Tilesius, 1815), på noen lokaliteter in Finnmark. MSc thesis, UIT The Arctic University of Norway, Tromsø

Hill BJ (1976) Natural food, foregut clearance-rate and activity of crab Scylla serrata. Mar Biol 34:109-116

*Holt RD, Lawton JH (1994) The ecological consequences of shared natural enemies. Annu Rev Ecol Syst 25: 495-520

Hood GM (2010) PopTools version 3.2.3. www.poptools.org

Houde ED (2002) Mortality. In: Fuiman LA, Werner RG (eds) Fishery science: the unique contribution of early life stages. Blackwell Science, Oxford, p 64-87

* Huse G, Toresen R (1996) A comparative study of the feeding habits of herring (Clupea harengus, Clupeidae, L) and capelin (Mallotus villosus, Osmeridae, Muller) in the Barents Sea. Sarsia 81:143-153

ICES (International Council for the Exploration of the Sea) (2011) Barents Sea capelin Stock Annex 9. In: Rep Arctic Fish Work Group (AFWG), 28 April-4 May, 2011, Hamburg, Germany. ICES CM 2011/ACOM 05. ICES, Copenhagen

ICES (2014) Barents Sea and Norwegian Sea capelin in subareas I and II, excluding division IIa west of $5^{\circ} \mathrm{W}$ (Barents Sea capelin). In: Rep ICES Advis Comm, ICES Advice, Book 3, Chapter 3.3.1. ICES, Copenhagen, p 1-12

ICES (2016) Barents Sea capelin. In: Rep Arctic Fish Work Group (AFWG), 19-25 April 2016. ICES CM 2016/ ACOM:06. ICES, Copenhagen

Ims RA (1990) In the adaptive value of reproductive synchrony as a predator-swamping strategy. Am Nat 136: 485-498

Jewett SC, Feder HM (1982) Food and feeding habits of the king crab Paralithodes camtschatica near Kodiak Island, Alaska. Mar Biol 66:243-250

Jobling M (1986) Mythical models of gastric and implications for food consumption studies. Environ Biol Fishes $16: 35-50$

Jørgensen LL (2005) Impact scenario for an introduced decapod on Arctic epibenthic communities. Biol Invasions 7: 949-957

Jørgensen LL, Nilssen EM (2011) The invasive history, impact and management of the red king crab Paralithodes camtschaticus off the coast of Norway. In: Galil BS, Clark PF, Carlton JT (eds) In the wrong place-alien marine crustaceans: distribution, biology and impacts, 6 . Springer, Dordrecht, p 521-536

* Jørgensen LL, Primicerio R (2007) Impact scenario for the invasive red king crab Paralithodes camtschaticus (Tilesius, 1815) (Reptantia, Lithodidae) on Norwegian, native, epibenthic prey. Hydrobiologia 590:47-54

Kempf A, Floeter J, Temming A (2008) Predator-prey overlap induced Holling type III functional response in the North Sea fish assemblage. Mar Ecol Prog Ser 367: 295-308

* Leggett WC, DeBlois E (1994) Recruitment in marine fishes: is it regulated by starvation and predation in the egg and larval stages? Neth J Sea Res 32:119-134 
Lønning S, Kjørsvik E, Falk-Petersen IB (1988) A comparative study of pelagic and demersal eggs from common marine fishes in Northern Norway. Sarsia 73:49-60

Majaneva S, Berge J, Renaud PE, Vader A and others (2013) Aggregations of predators and prey affect predation impact of the Arctic ctenophore Mertensia ovum. Mar Ecol Prog Ser 476:87-100

Maynou F, Cartes JE (1998) Daily ration estimates and comparative study of food consumption in nine species of deep-water decapod crustaceans of the NW Mediterranean. Mar Ecol Prog Ser 171:221-231

Michelsen HK (2011) Prey selection of the red king crab (Paralithodes camtschaticus) preying on lumpfish eggs (Cyclopterus lumpus), sea urchins (Strongylocentrotus droebachiensis) and scallops (Chlamys clamys islandica). MSc thesis, UIT The Arctic University of Norway, Tromsø

Mikkelsen N (2013) Predation on the demersal fish eggs of capelin Mallotus villosus and lumpsucker Cyclopterus lumpus in relation to recruitment. $\mathrm{PhD}$ thesis, UiT The Arctic University of Norway, Tromsø

Mikkelsen N, Pedersen T (2012) Invasive red king crab affects lumpsucker recruitment by egg consumption. Mar Ecol Prog Ser 469:87-99

Nakashima BS, Wheeler JP (2002) Capelin (Mallotus villosus) spawning behaviour in Newfoundland waters - the interaction between beach and demersal spawning. ICES J Mar Sci 59:909-916

Nilsson J (2006) Predation of northern pike (Esox lucius L.) eggs: a possible cause of regionally poor recruitment in the Baltic Sea. Hydrobiologia 553:161-169

Olson RJ, Boggs C (1986) Apex predation by yellowfin tuna (Thunnus albacares): independent estimates from gastric evacuation and stomach contents, bioenergetics, and cesium concentrations. Can J Fish Aquat Sci 43:1760-1775

Orlov YI, Ivanov BG (1978) On the introduction of the Kamchatka crab Paralithodes camtschatica (Decapoda: Anomura: Lithodidae) into the Barents Sea. Mar Biol 48: 373-375

Pavlova LV (2008) Effect of juvenile red king crabs on zoobenthos in Kola Bay (Barents Sea). Dokl Biol Sci 422: 312-315

Pavlova LV (2009) Estimation of foraging on the sea urchin Strongylocentrotus droebachiensis (Echinoidea: Echinoida) by the red king crab Paralithodes camtschaticus (Malacostraca: Decapoda) in coastal waters of the Barents Sea. Biol Morya 35:288-295

Rankine PW, Morrison JA (1989) Predation on herring larvae and eggs by sand-eels Ammodytes marinius (Rait) and Hyperoplus lanceolatus (Lesauvage). J Mar Biol Assoc UK 69:493-498

Editorial responsibility: James McClintock, Birmingham, Alabama, USA
Sætre R, Gjøsæter J (1975) Ecological investigations on the spawning grounds of the Barents Sea capelin. Fiskeridir Skr (Havunders) 16:203-227

Sarda F, Valladares FJ (1990) Gastric evacuation of different foods by Nephrops norvegicus (Crustacea:Decapoda) and estimation of soft tissue ingested, maximum food intake and cannibalism in captivity. Mar Biol 104:25-30

Slotte A, Mikkelsen N, Gjøsæter H (2006) Egg cannibalism in Barents Sea capelin in relation to a narrow spawning distribution. J Fish Biol 69:187-202

Stiansen S, Ferno A, Furevik D, Jørgensen T, Løkkeborg S (2010) Horizontal and vertical odor plume trapping of red king crabs explains the different efficiency of top- and side-entrance pot designs. Trans Am Fish Soc 139:483-490

Sundet JH, Berenboim B (2008) Research on the red king crab (Paralithodes camtschaticus) from the Barents Sea in 2005-2007. IMR/PINRO Joint Rep Ser 3/2008. Institute of Marine Research, Bergen

Sundet JH, Hjelseth AM (2010) Seasonal depth distribution of the red king crab (Paralithodes camtschaticus) in Varangerfjorden, Northern Norway. In: Kruse GH, Eckert GL, Foy RJ, Lipcius RN, Sainte-Marie B, Stram DL, Woodby D (eds) Biology and management of exploited crab populations under climate change. 25th Lowell Wakefield Fish Symp. Alaska Sea Grant College Program, University of Alaska Fairbanks, Fairbanks, AK, p 403-412

Sundet JH, Rafter EE, Nilssen EM (2000) Sex and seasonal variation in the stomach content of the red king crab, Paralithodes camtschaticus in the southern Barents Sea. In: Klein JCV, Schram FR (eds) Biodiversity crisis and Crustacea, Book 12. Balkema Publishers, Leiden, p 193-200

Tarverdieva MI (1978) Diurnal feeding rhythm of the king crab Paralithodes camtschatica. Biol Morya 3:91-95

Templeman W (1948) The life history of capelin (Mallotus villosus O.F.Müller) in Newfoundland waters. Bull Newfoundl Gov Lab 17:1-151

Tschanz B, Bersier LF, Bacher S (2007) Functional responses: a question of alternative prey and predator density. Ecology 88:1300-1308

Windsland K, Hvingel C, Nilssen EM, Sundet JH (2014) Dispersal of the introduced red king crab (Paralithodes camtschaticus) in Norwegian waters: a tag-recapture study. ICES J Mar Sci 71:1966-1976

Zar JH (1999) Biostatistical analysis. Prentice-Hall, Upper Saddle River, NJ

Zhou S, Shirley TC (1997) Behavioural responses of red king crab to crab pots. Fish Res 30:177-189

Zuur AF, Ieno EN, Smith GM (2007) Analysing ecological data. Springer, New York, NY

Submitted: May 27, 2016; Accepted: November 1, 2016 Proofs received from author(s): December 22, 2016 